\title{
Low red/far-red ratio as a signal promotes carbon assimilation of soybean seedlings by increasing the photosynthetic capacity
}

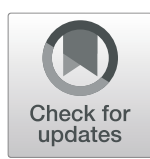

Feng Yang ${ }^{1,2,3^{*}}$, Qinlin Liu', Yajiao Cheng ${ }^{1,2}$, Lingyang Feng ${ }^{1,2}$, Xiaoling $\mathrm{Wu}^{1,2,3}$, Yuanfang Fan ${ }^{1,2}$, Muhammad Ali Raza ${ }^{1,2}$, Xiaochun Wang ${ }^{1,2,3}$, Taiwen Yong ${ }^{1,2,3}$, Weiguo Liu ${ }^{1,2,3}$, Jiang Liu ${ }^{1,2,3}$, Junbo Du $u^{1,2,3}$, Kai Shu $u^{1,2,3}$ and Wenyu Yang ${ }^{1,2,3^{*}}$

\begin{abstract}
Background: Shading includes low light intensity and varying quality. However, a low red/far-red (R/Fr) ratio of light is a signal that affects plant growth in intercropping and close- planting systems. Thus, the low R/Fr ratio uncoupling from shading conditions was assessed to identify the effect of light quality on photosynthesis and $\mathrm{CO}_{2}$ assimilation. Soybean plants were grown in a growth chamber with natural solar radiation under four treatments, that is, normal (N, sunlight), N + Fr, Low $(L)+F r$, and L light.

Results: Low R/Fr ratio significantly increased the total biomass, leaf area, starch and sucrose contents, chlorophyll content, net photosynthetic rate, and quantum efficiency of the photosystem II compared with normal R/Fr ratio under the same light level $(P<0.05)$. Proteomic analysis of soybean leaves under different treatments was performed to quantify the changes in photosynthesis and $\mathrm{CO}_{2}$ assimilation in the chloroplast. Among the 7834 proteins quantified, 12 showed a $>1.3$-fold change in abundance, of which 1 was related to porphyrin and chlorophyll metabolism, 2 were involved in photosystem I (PS I), 4 were associated with PS II, 3 proteins participated in photosynthetic electron transport, and 2 were involved in starch and sucrose metabolism. The dynamic change in these proteins indicates that photosynthesis and $\mathrm{CO}_{2}$ assimilation were maintained in the $\mathrm{L}$ treatment by up-regulating the component protein levels compared with those in $\mathrm{N}$ treatment. Although low $\mathrm{R} / \mathrm{Fr}$ ratio increased the photosynthetic $\mathrm{CO}_{2}$ assimilation parameters, the differences in most protein expression levels in $\mathrm{N}+\mathrm{Fr}$ and $\mathrm{L}+\mathrm{Fr}$ treatments compared with those in $\mathrm{N}$ treatment were insignificant. Similar trends were found in gene expression through quantitative reverse transcription polymerase chain reaction excluding the gene expression of sucrose synthase possible because light environment is one of the factors affecting carbon assimilation.
\end{abstract}

Conclusions: Low R/Fr ratio (high Fr light) can increase the photosynthetic $\mathrm{CO}_{2}$ assimilation in the same light intensity by improving the photosynthetic efficiency of the photosystems.

Keywords: Light quality, Intercropping, Soybean, Shade, Photosynthesis, $\mathrm{CO}_{2}$ assimilation

\footnotetext{
*Correspondence: f.yang@sicau.edu.cn; mssiyangwy@sicau.edu.cn

${ }^{1}$ College of Agronomy, Sichuan Agricultural University, Huimin Road 211,

Wenjiang District, Chengdu 611130, People's Republic of China

Full list of author information is available at the end of the article
}

(c) The Author(s). 2020 Open Access This article is licensed under a Creative Commons Attribution 4.0 International License, which permits use, sharing, adaptation, distribution and reproduction in any medium or format, as long as you give appropriate credit to the original author(s) and the source, provide a link to the Creative Commons licence, and indicate if changes were made. The images or other third party material in this article are included in the article's Creative Commons licence, unless indicated otherwise in a credit line to the material. If material is not included in the article's Creative Commons licence and your intended use is not permitted by statutory regulation or exceeds the permitted use, you will need to obtain permission directly from the copyright holder. To view a copy of this licence, visit http://creativecommons.org/licenses/by/4.0/ The Creative Commons Public Domain Dedication waiver (http://creativecommons.org/publicdomain/zero/1.0/) applies to the data made available in this article, unless otherwise stated in a credit line to the data. 


\section{Background}

Light is an essential factor for crop growth and development in agricultural production [1]. Intra- or interspecies plant mutual shading often affects crop light interception [2], especially in intercropping and close planting system which are important cultivation methods in increasing resource utilization and yield [3]. Plants can perceive shading that enable them to acclimate and adjust their phenotypic and physiological characteristics to compete for limited light resource [4]. Shade often leads to elongation responses in the stem, petioles, and leaves in shadesensitive plant species [5].

Plant shading reduces the amount of photosynthetically active radiation (PAR) and changes the spectral composition of light $[6,7]$. Plants selectively absorb red (R) wavelengths through photosynthetic pigments. The far-red $(\mathrm{Fr})$ spectrum is relatively enriched due to radiation reflected and transmitted by the green leaves of neighboring plants [8]. A resulting decrease in $\mathrm{R} / \mathrm{Fr}$ ratio in the surrounding environment is observed. The changes in light intensity and quality under shade differ from those under low light condition [9, 10]. Low light conditions achieved using black nylon nets or fabrics do not alter the spectral composition of light, particularly the $\mathrm{R} / \mathrm{Fr}$ ratio $[11,12]$.

Phytochromes play a key role in the perception of the $\mathrm{R} / \mathrm{Fr}$ ratio signal and regulation of the plant photomorphogenesis via gene expression and physiological processes [1]. Phytochromes exist in two forms, that is, $\mathrm{R}$ light absorbing Pr and Fr light absorbing Pfr $[1,5]$. The equilibrium between these two forms dynamically changes with the change in composition of the light spectrum within the $300-800 \mathrm{~nm}$ range [13]. A low $\mathrm{R} / \mathrm{Fr}$ ratio is an important signal factor in shade avoidance [14]. Responses to low $\mathrm{R} / \mathrm{Fr}$ ratio include increased stem elongation, decreased leaf area and branching, and changes in chlorophyll (Chl) content $[8,15,16]$. Low R/ Fr ratio in normal or low light condition significantly increases the soybean biomass (dry weight) compared with normal R/Fr ratio (approximately 1.2) [6, 9].

A low $\mathrm{R} / \mathrm{Fr}$ ratio indicates high enrichment of the $\mathrm{Fr}$ light spectrum in the plant canopy. Plant leaves absorb less amount of Fr light $(\lambda>700 \mathrm{~nm})$; therefore, it contributes less towards the quantum yield of photosynthesis [17]. However, Zhen and van Iersel [18] reported that Fr light is required for efficient photochemistry and photosynthesis. Similarly, the Fr light of the shade is higher than that of low light, thereby increasing the net photosynthesis rate $\left(P_{\mathrm{n}}\right)$ under the same light intensity condition [11], resulting in increased the whole-plant net assimilation $[6,9]$. Typically, a shorter wavelength is used with longer wavelengths to enhance its photosynthetic efficiency, and this overall phenomenon is called the Emerson enhancement effect [18]. The reverse effect, which is the enhancement of the quantum yield of short light wavelength by $\mathrm{Fr}$ light (e.g., at low $\mathrm{R} / \mathrm{Fr}$ ratio) in different light intensity environments, has not received considerable attention. Some studies only indicate that Fr light can increase plant photosynthesis and biomass $[6,18]$. Therefore, in uncoupling $\mathrm{R} / \mathrm{Fr}$ ratio from shade, whether low R/Fr ratio (Fr light enrichment) in different light intensity regulates the photomorphogenic process needs further analysis.

Photosystems I and II (PS I and II, respectively) operate in series to carry out the primary photochemical reactions of photosynthesis [18]. These processes are involved in light absorption and energy and electron transfer, which are carried out by different related proteins $[11,19]$. Proteomic analysis has been used to identify changes in plant photosynthetic proteins in salt stress [20], water deficit [21], low phosphate [22], and chlorophyll deficient [23]. We previously investigated the response of soybean photosynthetic proteins to shade condition by using isobaric tagging for the relative and absolute quantification (iTRAQ) approach [11]. However, to our best knowledge, the proteomic analysis of photosynthesis in uncoupling light intensity and $\mathrm{R} / \mathrm{Fr}$ ratio from shade is important to determine the $\mathrm{R} / \mathrm{Fr}$ ratio regulating the photosystems related-proteins, which affect photosynthesis and $\mathrm{CO}_{2}$ assimilation.

Soybean (Glycine max (L.) Merr.) is one of the most important cultivated crops of protein and oil worldwide [24, 25], which is often used for rotation or to intercrop with other crops because it can fix atmospheric nitrogen [3]. However, soybean often suffer from intra- or interspecies mutual shading [9]. Shade increases the height but decreases the biomass, chlorophyll contents, and photosynthesis of soybean plant [2, 26]. Likewise, we previously reported the response of photosynthetic proteins to shade and low light by using iTRAQ-quantitative proteomic analysis, and found that Fr light enrichment of shade increases $P_{\mathrm{n}}$ by up-regulating the gene expression levels of differential proteins compared with low light [11]. Thus, low $\mathrm{R} / \mathrm{Fr}$ ratio may be a signal in promoting $\mathrm{CO}_{2}$ assimilation by increasing the photosynthetic capacity. Therefore, this work aims to analyze the soybean morphology, carbohydrate, and photosynthesis in response to low $\mathrm{R} / \mathrm{Fr}$ ratio in different light intensities and reveal the effect of low $\mathrm{R} /$ Fr ratio on soybean photosynthesis using the iTRAQ technique in different light intensities.

\section{Results}

\section{Morphological characteristics}

Low $\mathrm{R} / \mathrm{Fr}$ ratio directly affected soybean growth phenotype under normal or low light intensity (Fig. 1a). The plant height of soybean in the $\mathrm{N}+$ Fr treatment was significantly higher than that in the $\mathrm{N}$ treatment under normal light intensity. By contrast, the plant height in the 

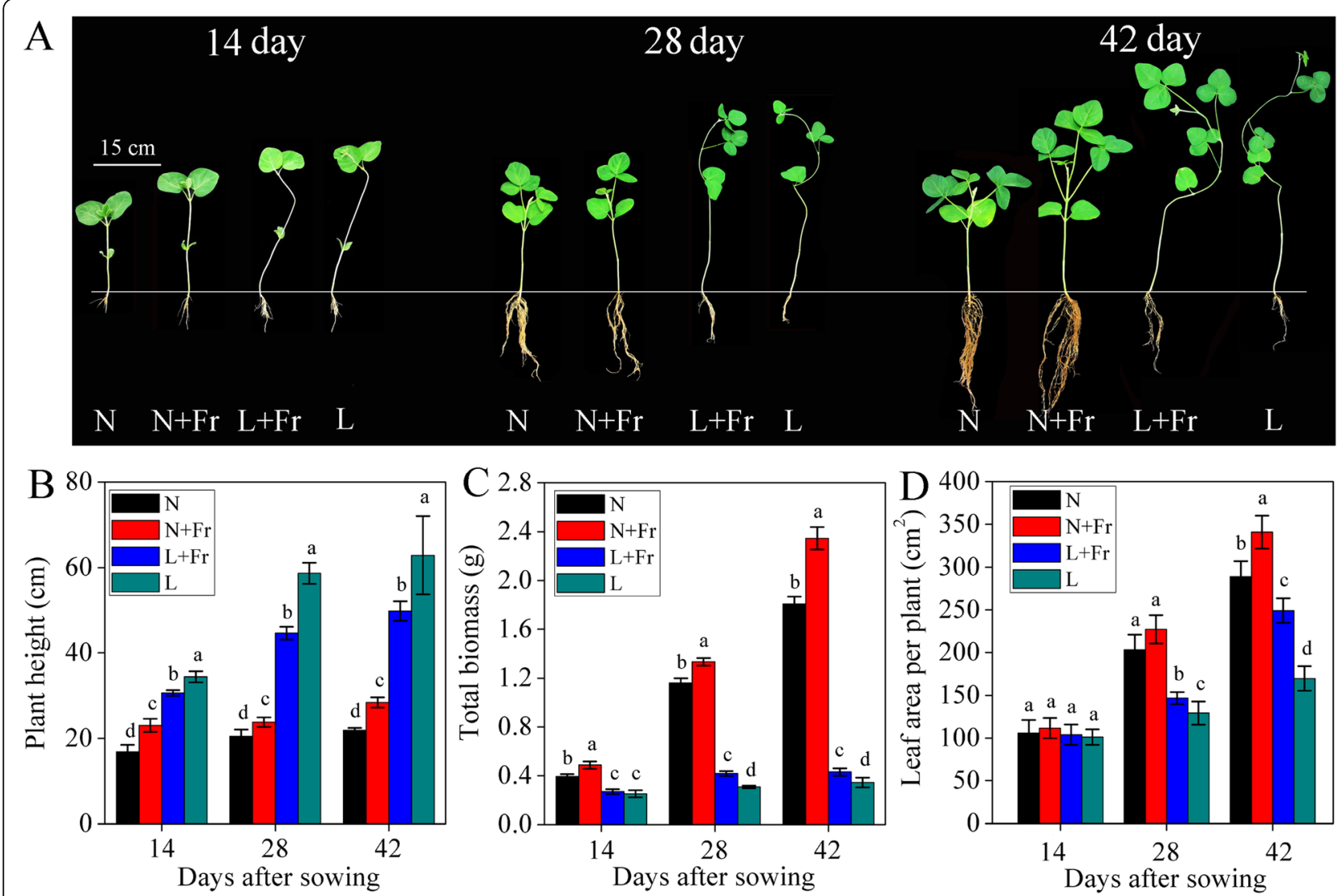

Fig. 1 Soybean growth performance (a), plant height (b), total biomass (c), and leaf area (d) under different treatments. N, N + Fr, $L+F r$, and $L$ denote normal light (normal PAR and normal R/Fr ratio), normal light plus far-red light (normal PAR and low R/Fr ratio), low light plus far-red light (low PAR and low R/Fr ratio), and low light (low PAR and normal R/Fr ratio), respectively. Each value was expressed as the mean \pm SD. The means for each treatment without common letters were significantly different at $P=0.05$ according to Duncan's multiple range test

$\mathrm{L}+$ Fr treatment was decreased by $20.8 \%$ compared with that of the $\mathrm{L}$ treatment in 42 days after sowing (Fig. 1b). After 14 days of sowing, the highest biomass values of soybean plants were found in treatments $\mathrm{N}+\mathrm{Fr}$ and $\mathrm{L}+$ Fr that those in $\mathrm{N}$ and $\mathrm{L}$. Soybean plants always produced maximum biomass in normal light treatments $(\mathrm{N}$ and $\mathrm{N}+\mathrm{Fr}$ ) as compared to those in low light treatments ( $\mathrm{L}$ and $\mathrm{L}+\mathrm{Fr}$ ). At 42 days after sowing, the maximum and minimum total biomasses were 2.4 and $0.3 \mathrm{~g} \mathrm{plant}^{-1}$ in the $\mathrm{N}+\mathrm{Fr}$ and $\mathrm{L}$ treatments, respectively. Similar trends on biomass were also found at 14 and 28 days after sowing under different treatments (Fig. 1c). In addition, low $\mathrm{R} / \mathrm{Fr}$ ratio significantly increased the leaf area per plant at 14 and 28 days after sowing under normal or low light intensity, the change in the trends of leaf area per plant were consistent with the total biomass in different treatments (Fig. 1d).

\section{Changes in chloroplast ultrastructure, sucrose and starch content}

When growing in different light environments, the changes in chloroplast ultrastructure were different, the chloroplast size in $\mathrm{N}$ and $\mathrm{N}+\mathrm{Fr}$ treatments were larger than those in L and L + Fr treatment (Fig. 2a). Starch grain size also exhibited a similar trend. The starch contents in $\mathrm{N}+\mathrm{Fr}$ and $\mathrm{L}+\mathrm{Fr}$ treatments were significantly higher than those in $\mathrm{N}$ and $\mathrm{L}$ treatments, respectively. The maximum and minimum starch content were 92.4 $\mathrm{mg} / \mathrm{g}$ in $\mathrm{N}+\mathrm{Fr}$ treatment and $69.2 \mathrm{mg} / \mathrm{g}$ in L treatment, respectively. The sucrose content of soybean growing in $\mathrm{N}+\mathrm{Fr}$ treatment was significantly higher than those in other treatments (Fig. 2b).

\section{Chlorophyll content, photosynthesis, and quantum yield of PS II}

The Chl $a$, Chl $b$, and total Chl in normal light condition ( $\mathrm{N}$ and $\mathrm{N}+\mathrm{Fr}$ treatments) were significantly lower than those in low light ( $\mathrm{L}$ and $\mathrm{L}+\mathrm{Fr}$ treatment) (Fig. 3). The total Chl contents in $\mathrm{N}+\mathrm{Fr}$ and $\mathrm{L}+\mathrm{Fr}$ treatments (low $\mathrm{R} / \mathrm{Fr}$ ratio) were significantly increased by 6.5 and $14.3 \%$ compared with those in $\mathrm{N}$ and $\mathrm{L}$ treatments (normal $\mathrm{R} /$ Fr ratio), respectively.

The light response curves of the assimilation rate vs. the photosynthetic photon flux density (PPFD) and the 

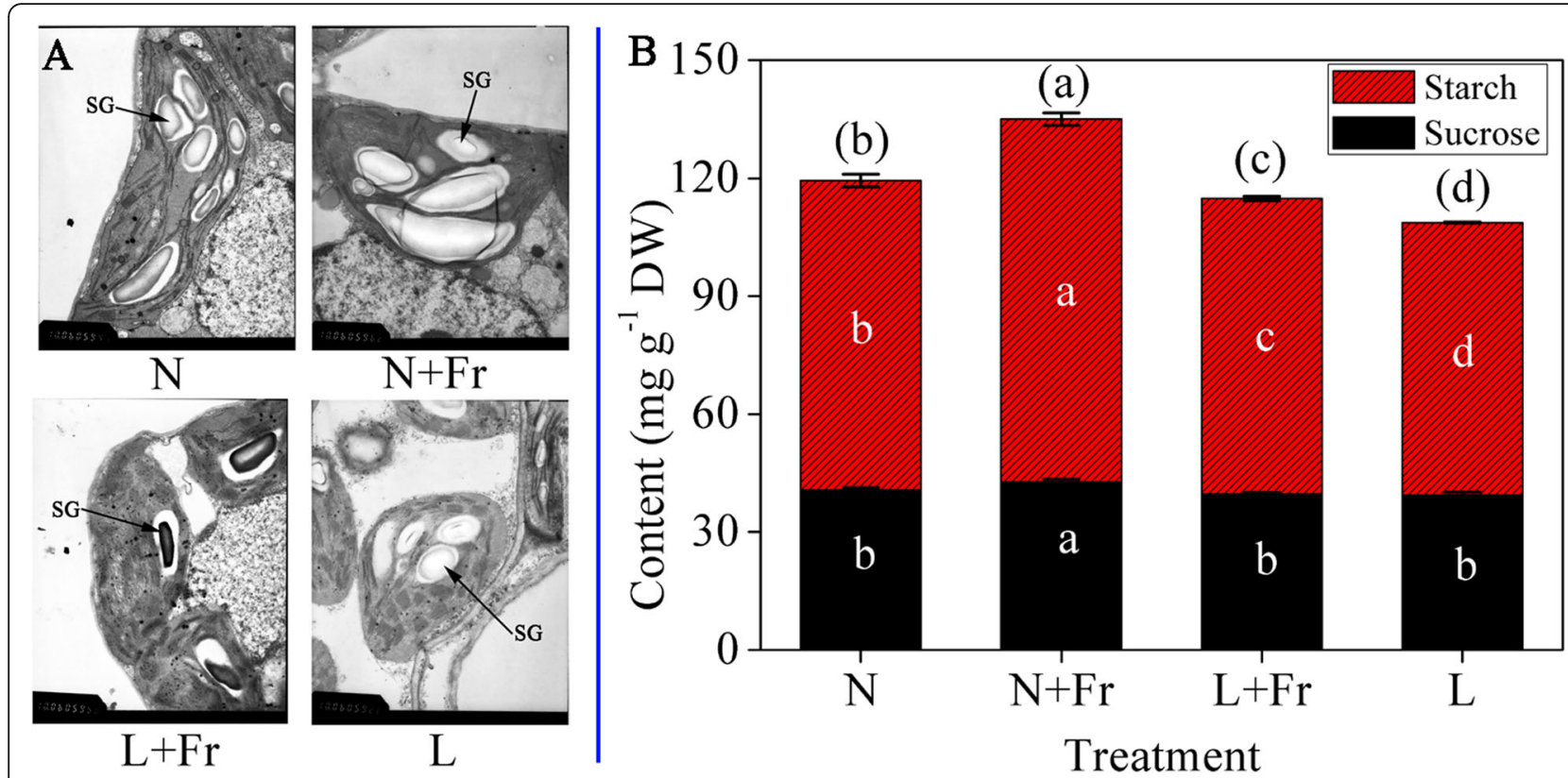

Fig. 2 Soybean chloroplast ultrastructure (a), starch and sucrose contents (b) under different treatments. $N, N+F r$, $L+F r$, and $L$ denote normal light (normal PAR and normal R/Fr ratio), normal light plus far-red light (normal PAR and low R/Fr ratio), low light plus far-red light (low PAR and low R/Fr ratio), and low light (low PAR and normal R/Fr ratio), respectively. SG stands for starch grain. Data are expressed as the means \pm SD of triplicates. Means followed by different letters are significantly different at $P=0.05$

quantum yield of PSII in four treatments were shown in Fig. S1 (data cited from our previous report [9]). Significant differences were found in the assimilation rates of the four treatments when PPFD was higher than $200 \mu \mathrm{mol}$ $\mathrm{m}^{-2} \mathrm{~s}^{-1}$. The maximum values of photosynthetic rate $\left(P_{\max }\right)$ and light saturation point (LSP) appeared in $\mathrm{N}+\mathrm{Fr}$

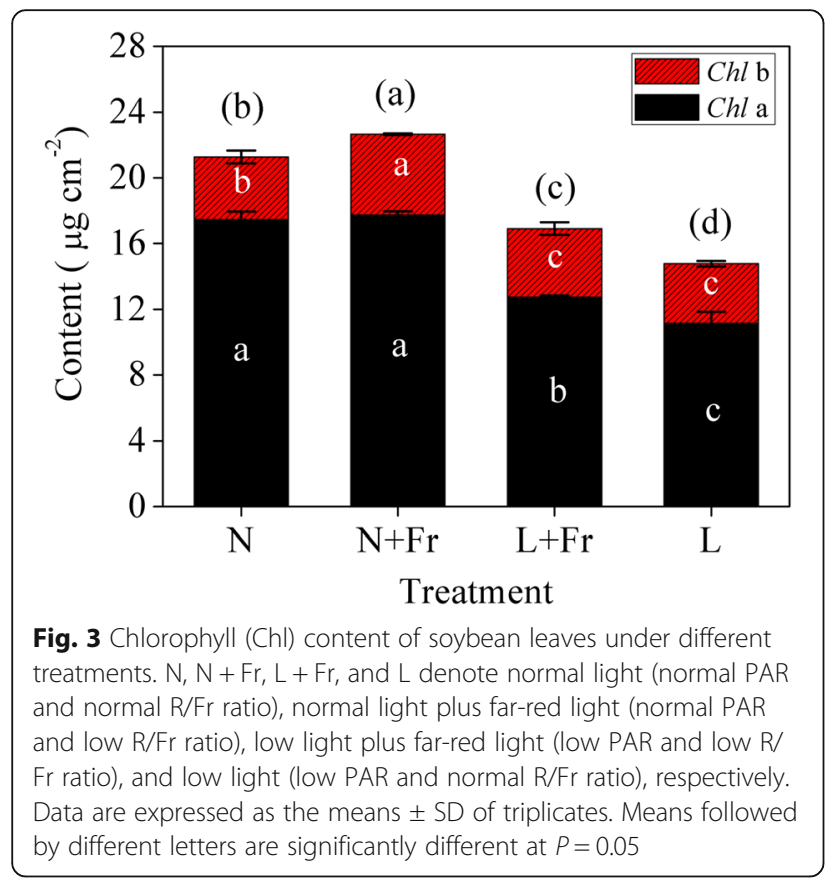

treatment compared with those in other treatments. $P_{\max }$ and LSP under $\mathrm{N}$ treatment were 14.9 and $47.4 \%$ lower than the corresponding values under $\mathrm{N}+\mathrm{Fr}$ treatment, respectively. Similarly, $P_{\max }$ and LSP under L treatment were 23.8 and $38.2 \%$ lower than those under $\mathrm{L}+$ Fr treatment, respectively. The minimum values of $P_{\max }$ and LSP appeared in $\mathrm{L}$ treatment compared with those in other treatments, were $5.8 \mu \mathrm{mol} \mathrm{CO} \mathrm{C} \mathrm{m}^{-2} \mathrm{~s}^{-1}$ in the $318.2 \mu \mathrm{mol}$ $\mathrm{m}^{-2} \mathrm{~s}^{-1}$, respectively. In this study, the quantum yields of PSII in treatments $\mathrm{N}$ and $\mathrm{N}+\mathrm{Fr}$ was noted significantly higher than those in $\mathrm{L}$ and $\mathrm{L}+\mathrm{Fr}$ treatments. However, treatment $\mathrm{L}+\mathrm{Fr}$ enhanced the quantum yields of PSII by $15.2 \%$ as compared to those in treatment $\mathrm{L}$.

\section{Soybean leaf proteomic analysis}

The total protein of the soybean leaves was extracted from different treatments, and the protein profiles were explored using the iTRAQ technique. A total of 9890 protein groups were identified, among which 7834 proteins were quantified (Table S1). On the basis of at least $>1.3$ - of fold change $(P<0.05)$, among the quantified proteins, we observed that 15 and 41 proteins were upregulated and down-regulated, respectively in $\mathrm{N}+\mathrm{Fr}$ vs. N; 102 and 548 were up-regulated and down-regulated, respectively under $\mathrm{L}+\mathrm{Fr}$ vs. N, 180 and 183 proteins were up-regulated and down-regulated, respectively in $\mathrm{L}$ vs. N (Fig. 4a).

Based on Gene Ontology (GO) enrichment analysis, differentially accumulated proteins were categorized into 

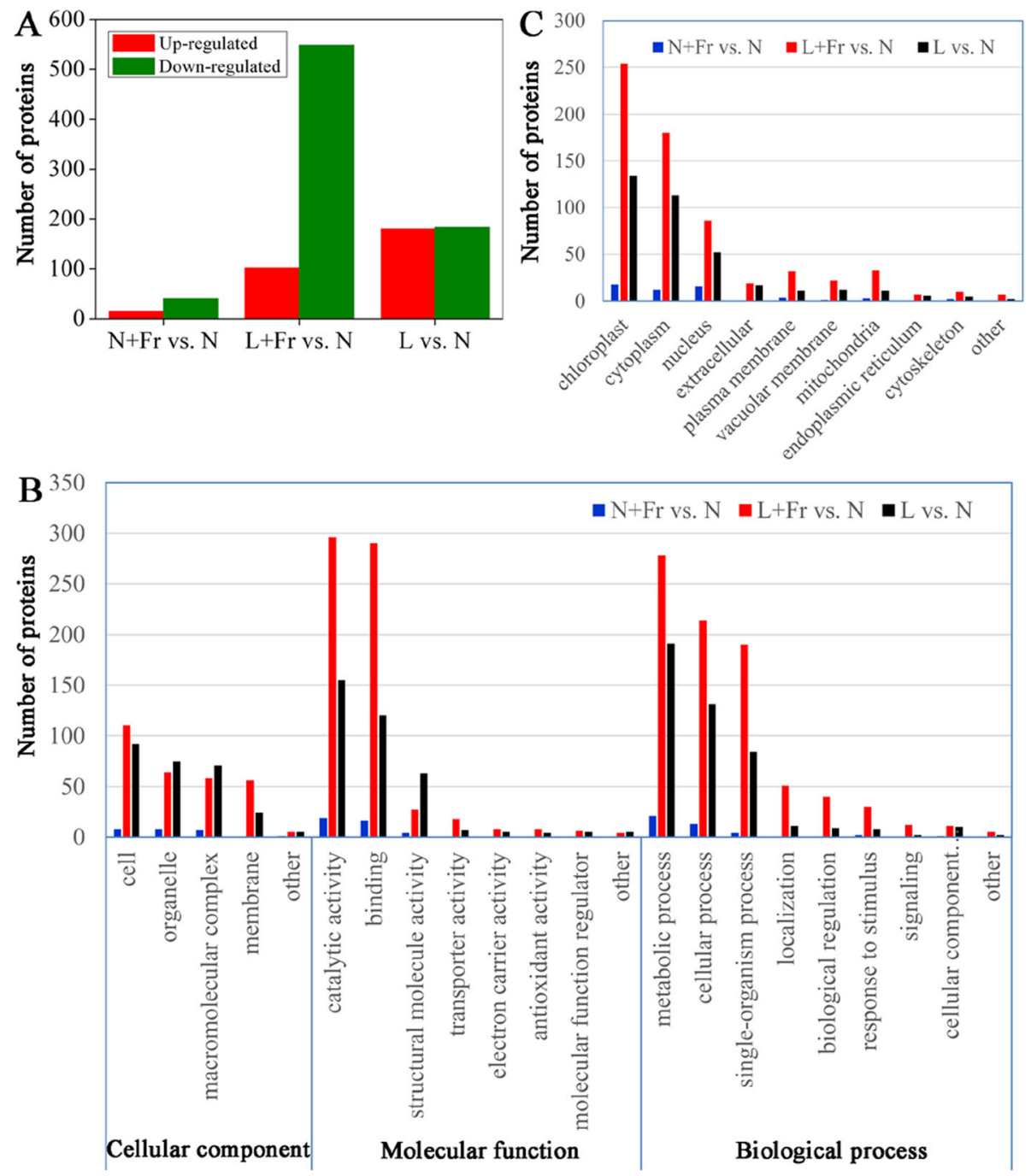

Fig. 4 Differential protein expression analyses of soybean leaves under different light environments. a Histogram of the up- and down-regulated protein number under normal light plus far-red light $(N+F r)$, low light plus far-red light $(L+F r)$, and $L$ conditions compared with those under $N$ condition. $\mathbf{b}$ GO classification of differentially accumulated proteins. $\mathbf{c}$ The subcellular classification of the differentially accumulated protein number under $N+F r$, $L+F r$, and $L$ treatments compared with that under $N$ treatment

three main groups, including biological process, molecular function, and cellular components (Fig. 4b). Biological process and molecular function categories were further divided into three sub-categories representing cellular, metabolic, and single-organism processes and binding, catalytic and structural molecule activity, respectively. The subcellular location annotation information illustrated that among all of the identified proteins, the associated chloroplast proteins accounted for 36.9, 39.1 , and $32.1 \%$ of the unique proteins in $\mathrm{L}$ vs. $\mathrm{N}, \mathrm{L}+\mathrm{Fr}$ vs. N, and N + Fr vs. N, respectively (Fig. 4c).

Kyoto Encyclopedia of Genes and Genomes (KEGG) pathways visualized as heat map through a two-tailed Fisher's exact test were used to identify the differences in protein abundance among $\mathrm{L}+\mathrm{Fr}, \mathrm{N}+\mathrm{Fr}, \mathrm{N}$, and $\mathrm{L}$ treatments. Thirteen different functional categories were selected for analysis. As illustrated in Fig. 5, among the functional categories, $\mathrm{C}$ metabolism and photosynthesisantenna proteins were related to photosynthetic $\mathrm{CO}_{2}$ assimilation. The proteins involved in photosynthesis in $\mathrm{N}+\mathrm{Fr}$ and $\mathrm{L}+\mathrm{Fr}$ treatments were down-accumulated compared with those in $\mathrm{N}$ treatment, whereas proteins in $\mathrm{L}$ treatment were up-accumulated.

\section{Key protein associated with photosynthesis assimilation of soybean leaves in response to different light conditions}

A total of 12 differentially expressed proteins related to photosynthetic $\mathrm{CO}_{2}$ assimilation were detected by iTRAQ analysis under $\mathrm{N}+\mathrm{Fr}, \mathrm{L}+\mathrm{Fr}$, and $\mathrm{L}$ treatments 


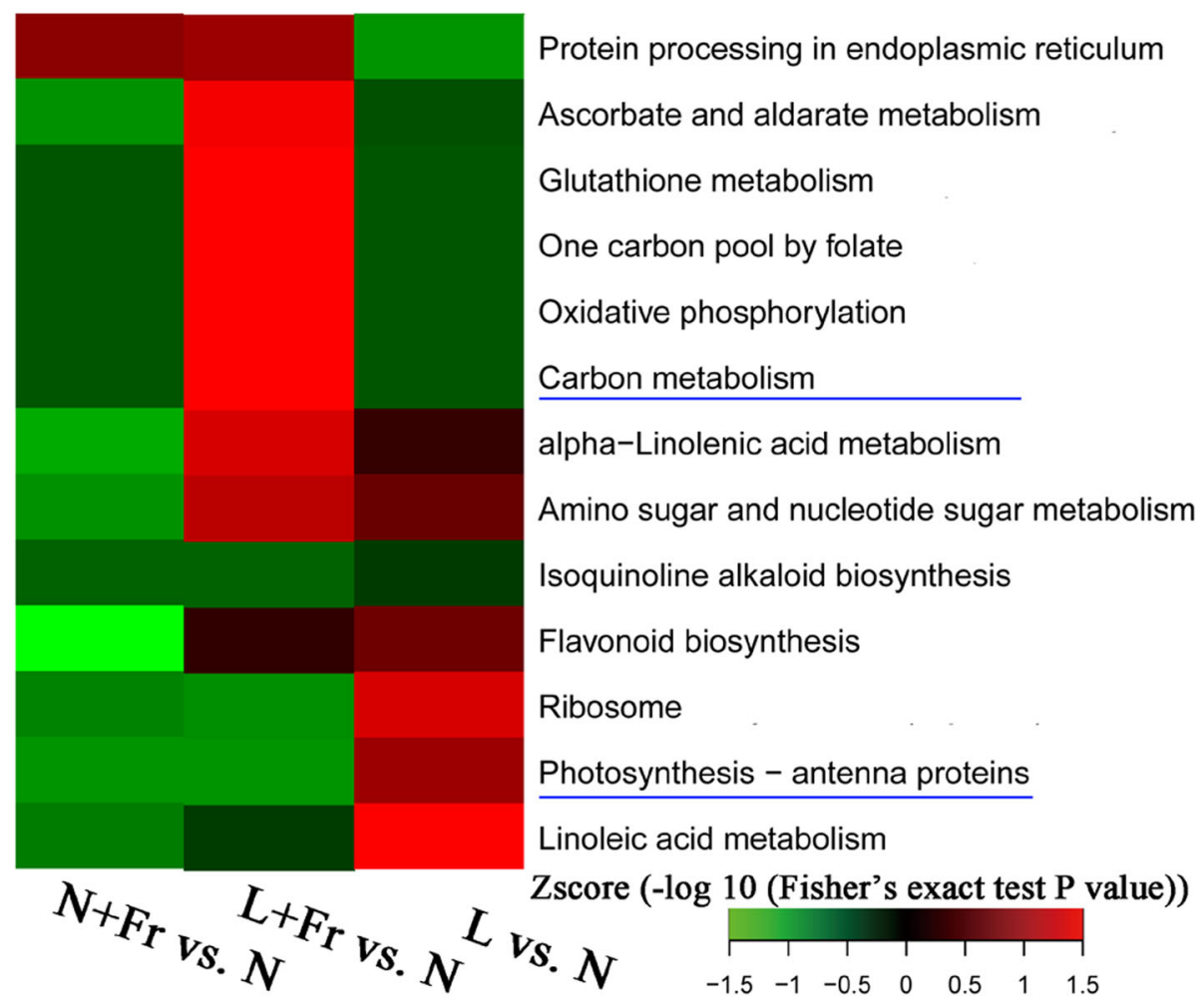

Fig. 5 KEGG pathway-based enrichment analysis of differentially accumulated proteins. $N, N+F r, L+F r$, and $L$ denote normal light (normal PAR and normal R/Fr ratio), normal light plus far-red light (normal PAR and low R/Fr ratio), low light plus far-red light (low PAR and low R/Fr ratio), and low light (low PAR and normal R/Fr ratio), respectively. Red colors indicate up-accumulated proteins and green colors indicate down-accumulated proteins in the $N+F r, L+F r$, and $L$ treatments compared with the $N$ treatment

Table 1 Differentially expressed proteins associated with soybean photosynthetic $\mathrm{CO}_{2}$ assimilation under different light environments

\begin{tabular}{|c|c|c|c|c|}
\hline Accession no. & Description & $N+$ Fr vs. $N$ & $L+F r$ vs. $N$ & L vs. N \\
\hline \multicolumn{5}{|c|}{ Porphyrin and chorophyll metabolism } \\
\hline AOA0R4J3L3 & Protochlorophyllide reductase (POR) & 0.75 & / & 2.72 \\
\hline \multicolumn{5}{|l|}{ Photosystem I } \\
\hline A5Z2K3 & Photosystem I subunit (PsaD) & / & / & 1.38 \\
\hline \multicolumn{5}{|l|}{ Photosystem II } \\
\hline AOAOR4J513 & Chlorophyll a/b binding protein 1 (Lhcb 1) & 0.37 & / & 3.80 \\
\hline Q93YG3 & Chlorophyll a/b binding protein 2 (Lhcb 2) & / & / & 1.52 \\
\hline I1JLHO & Chlorophyll a/b binding protein 4 (Lhcb 4) & / & / & 1.44 \\
\hline I1KR46 & Chlorophyll a/b binding protein 6 (Lhcb 6) & / & / & 1.44 \\
\hline \multicolumn{5}{|c|}{ Photosynthetic electron transport } \\
\hline C6SVRO & Plastocyanin (PetE) & / & / & 1.46 \\
\hline С6T1」0 & Ferredoxin-1 (PetF) & / & / & 1.38 \\
\hline 11JCG8 & Ferredoxin-NADP reductase (PetH) & / & 0.44 & / \\
\hline \multicolumn{5}{|c|}{ Starch and sucrose metabolism } \\
\hline $11 \mathrm{MBQ9}$ & Sucrose synthase (SS) & / & 1.42 & 1.92 \\
\hline I1KAT2 & Starch synthase (GlgA) & / & 0.60 & / \\
\hline
\end{tabular}

"/" indicates insignificant accumulation 
compared with those detected in $\mathrm{N}$ treatment. Among these differentially expressed proteins, one protein was related to porphyrin and chlorophyll metabolism, two proteins were involved in PS I, four proteins were associated with PS II, three proteins participated in photosynthetic electron transport, and two proteins were involved in starch and sucrose metabolism (Table 1). The expression levels of nine proteins (i.e., Protochlorophyllide reductase [POR], Photosystem I subunit [PsaD], Chlorophyll a/b binding protein 1 [Lhcb 1], Lhcb 2, Lhcb 4, Lhcb 6, PetE, PetF, and Sus) were up-regulated under $\mathrm{L}$ treatment compared with $\mathrm{N}$ treatment. However, the expression levels of the two proteins (i.e., POR and Lhcb 1) in $\mathrm{N}+\mathrm{Fr}$ treatment and two proteins (i.e., $\mathrm{PsaH}$ and $\mathrm{PetH}$ ) in $\mathrm{L}+\mathrm{Fr}$ treatment were downregulated compared with those in $\mathrm{N}$ treatment.

Real-time quantitative polymerase chain reaction (qRTPCR) results confirming the differentially expressed proteins

To assess the validity of the iTRAQ data, we randomly selected six gene products, including the POR, PsaD, Lhcb 1, PetE, and Sus gene expressed levels, according to differential protein classification for RT-PCR analysis, (Fig. 6). The qRT-PCR results showed that under L treatment, significant increase in the transcript level was observed for POR, PsaD, Lhcb 1, and PetE compared with $\mathrm{N}$ treatment. The POR, PsaD, and PetE expression levels were up-regulated under L + Fr treatment. By contrast, the expressions levels of POR, PsaD, and Lhcb 1 were down-regulated under $\mathrm{N}+$ Fr treatment compared with those under $\mathrm{N}$ treatment. The change in the Gmss
1 was different from that of POR in $\mathrm{N}+\mathrm{Fr}, \mathrm{L}+\mathrm{Fr}$, and $\mathrm{L}$ treatments.

\section{Discussion}

A low $\mathrm{R} /$ Fr ratio significantly increased the stem elongation of soybean under normal light intensity, while opposite trend was found under low light intensity (Fig. 1a and b). Light intensity regulates plant height compared with $\mathrm{R} /$ Fr ratio under low light condition [9, 27]. However, a low $\mathrm{R} / \mathrm{Fr}$ ratio significantly increased the total biomasses and leaf area of soybean under the same light intensity condition (Fig. 1c). Similarly, the whole plant biomass of geranium and snapdragon increases with additional Fr radiation (low R/Fr ratio) [6].

Photosynthesis is the basis for material accumulation. Low R/Fr ratio improved photosynthesis under normal or low light intensity condition. Similar to the reverse of Emerson enhancement effect [28], the photosynthetic efficiency of short wavelengths may be improved by increasing long wavelength. It has been observed that PSI responds to shorter wavelengths of light by exhibiting excitement compared to PSIl that directly affects the photochemistry [29]. Interestingly, different wavelengths of light can supplement the effects of each other by over exiting the PSl and PSIl alternatively [20]. In addition, Fr alleviates acceptor-side limitations and imposes donorside limitations on the electron flow in PSI, and thereby increases the fraction of oxidized P700. Thus, the $P_{\max }$ values in $\mathrm{N}+\mathrm{Fr}$ and $\mathrm{L}+\mathrm{Fr}$ treatments (high enrichment of Fr light) were significantly higher than those in $\mathrm{N}$ and $\mathrm{L}$ treatments, respectively. Although low light intensity significantly decreased the Chl content (Chl $a$ and $b$ )

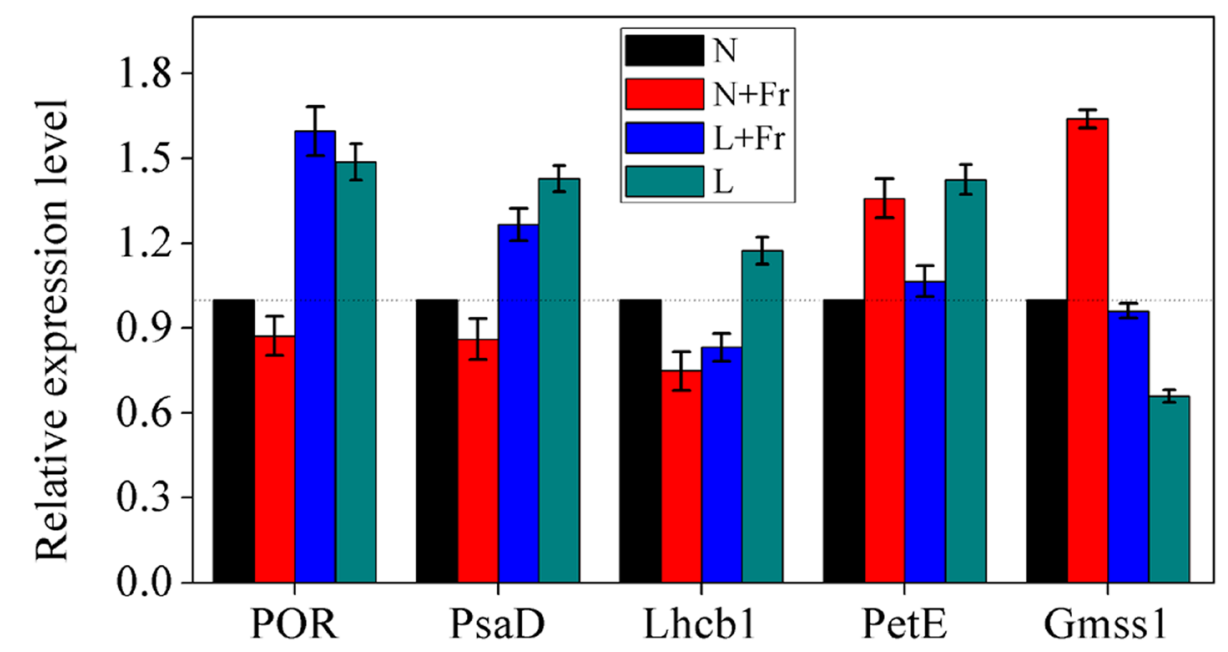

Fig. 6 Quantitative RT- PCR validations of the genes related to the differentially expressed proteins. N, N+Fr, $L+F r$, and $L$ denote normal light (normal PAR and normal R/Fr ratio), normal light plus far-red light (normal PAR and low R/Fr ratio), low light plus far-red light (low PAR and low $\mathrm{R} /$ Fr ratio), and low light (low PAR and normal R/Fr ratio), respectively. POR, PsaD, Lhcb 1, and PetE represent protochlorophyllide reductase, photosystem I subunit, chlorophyll a/b binding protein 1, and plastocyanin, respectively. Values are expressed as mean \pm SD $(n=3)$ 
compared with normal light condition, a low $\mathrm{R} / \mathrm{Fr}$ ratio significantly increased the $\mathrm{Chl}$ content per unit area under the same light level [16]. The changes in the trends of leaf area, Chl content, and $P_{n}$ were consistent with the total biomass in different treatments (Figs. 1, 3, $\mathrm{S} 1$ ), thereby indicating that low $\mathrm{R} / \mathrm{Fr}$ ratio might improve the photosynthetic capacity of soybean in the same light intensity.

In this study, a low $\mathrm{R} / \mathrm{Fr}$ ratio under $\mathrm{N}+\mathrm{Fr}$ and $\mathrm{L}+\mathrm{Fr}$ treatments can significantly increase the starch and sucrose content with respect to the corresponding values under $\mathrm{N}$ and $\mathrm{L}$ treatments, respectively (Fig. $2 \mathrm{~b}$ ). The complementation of shorter wavelengths of light with far-red light is responsible for the establishment of an excitation balance between two photosystems. This excitation balancing might optimize the rate of photochemistry and relative $\mathrm{CO}_{2}$ assimilation [20]. Similarly, the change in trends of starch and sucrose content in different treatments were similar to $P_{n}$, quantum yield of PSII, and total biomass (Figs. 1 and 2) [9]. In addition, the promotive effect of additional Fr radiation on photosynthesis and whole-plant net assimilation was previously reported in lettuce and geranium [12, 18]. Together, these results suggested that the high enrichment of $\mathrm{Fr}$ light possibly contributed to increased starch and sucrose contents by improving photosynthetic capacity of soybean leaves.

Proteomics is an approach for the systematic identification of all proteins expressed in a cell or tissue [30]. In this study, we mainly focused on the differentially expressed proteins related to photosynthesis (Table 1). The POR is the key functional protein in regulating chlorophyll metabolism [29, 31]. The POR protein expression was up-regulated under the $\mathrm{L}$ treatment relative to that under the $\mathrm{N}$ treatment, whereas an opposite trend was found in $\mathrm{N}+\mathrm{Fr}$ treatment (Table 1). POR expression significantly increased with the decrease in irradiance [32]. Our previous research also found that maize shade or low light can improve the POR protein expression [11]. The qRT-PCR analysis results confirmed the observed response of POR to different light intensities and qualities (Fig. 6). POR is a negative control protein of light-dependent response, especially for light intensity [33]. Although low R/Fr ratio in the same light intensity condition can improve the Chl contents per unit leaf area (Fig. 3), opposite trends were found in the POR protein and gene expression levels (Table 1; Fig. 6). This result was related to the unit $\left(\mathrm{mg} \mathrm{cm}^{-2}\right)$ of Chl contents [11, 34].

The PsaD subunit of PS I is a peripheral protein that provides a docking site for ferredoxin and interacts with other PS I subunits [35]. PsaD is highly sensitive to the light environment, and high light intensity significantly decreases the PsaD content [36]. Similarly, low light up- regulated the PsaD protein and gene expression levels because the high protein expression of PS II can improve the electron transport, which increases the PsaD protein expressions under low light condition [11]. The low R/Fr ratio (Fr light enhancement) may reverse the PsaD protein expression under low light condition (Table 2). This finding was similar to the results showing Fr light can improve the efficient photochemistry and photosynthesis [18].

The light-harvesting antenna (LHCII) is the major pigment- protein complex associated with PS II, thereby forming the PS II-LHCII supercomplex in which several LHCIIs surround the reaction center core complex [37]. The Lhcb levels decrease as light intensity increase with a significant trend for Lhcb 1, Lhcb 2, and Lhcb 4 [5, 6, 37]. Our results agreed with these data (Table 1). Similarly, the protein Lhcb 1 and Lhcb 2 expression levels decreased at excessive irradiance [38]. However, Lhcb 1, Lhcb 2, Lhcb 4, and Lhcb 6 levels remained unchanged under $\mathrm{L}+\mathrm{Fr}$ treatment (low $\mathrm{R} / \mathrm{Fr}$ ratio) compared with those under $\mathrm{N}$ treatment. Similar result also was found in the gene expression of Lhcb 1 (Fig. 6). These results indicated that increasing the Fr light wavelength (low R/ Fr ratio) can improve the photosynthetic efficiency under short wavelength. Ahmadova and Mamedov [39] indicated that the low energy of the Fr photons plays an important role in the photochemical progress.

PetE is one of the low molecular weight proteins which is involved in the cyclic and linear electron transport in oxygenic photosynthetic organisms. It catalyzes the electron transfer from the membrane-bound Cyt b6/ f complex to P700 [40]. PetH is a redox partner protein of PetF, which is a light-dependent electron transfer protein [41]. These proteins are highly sensitive to the light environment. Low light condition can up-regulate PetE and PetF expression (Table 1, Fig. 6). The changes in PetE and PetF protein trends were similar to those of Lhcb 1, Lhcb 2, Lhcb 4, and Lhcb 6 proteins under low light condition. This phenomenon may have occurred because the degree of increased thylakoid stacking improved the light capture and electron transport by upregulating relative proteins in low light compared with those in normal light (Table 1) [42]. However, the low $\mathrm{R} / \mathrm{Fr}$ ratio $(\mathrm{N}+\mathrm{Fr}$ and $\mathrm{L}+\mathrm{Fr}$ treatments) barely affected the PetE and PetF expression level compared with normal R/Fr ratio (normal light). This result was similar to the findings of our previous research [11]. The change in PetH expression was different from that of PetF under different treatments (Table 1 ), because PetH is ratecontrolling protein in the protein-protein interaction reaction between PetH and PetF as the electron transfer partner (Okada, 2009). This finding may explain why the chlorophyll $\mathrm{a} / \mathrm{b}$ binding proteins up-regulated in low light but $P_{n}$ decreased compared with other treatments (Fig. S1). 
Table $\mathbf{2}$ Light intensity and red/ far-red ratio of soybean canopy in different treatments

\begin{tabular}{lllll}
\hline Treatment & $N$ & $N+F r$ & $L+F r$ & $L$ \\
\hline PAR $\left(\mu \mathrm{mol} \cdot \mathrm{m}^{-2} \cdot \mathrm{s}^{-1}\right)$ & $566.50 \pm 2.24 \mathrm{a}$ & $566.57 \pm 1.84 \mathrm{a}$ & $64.22 \pm 0.68 \mathrm{~b}$ & $63.33 \pm 0.14 \mathrm{~b}$ \\
R/Fr ratio & $1.33 \pm 0.081 \mathrm{a}$ & $0.42 \pm 0.05 \mathrm{~b}$ & $0.08 \pm 0.012 \mathrm{C}$ & $1.26 \pm 0.027 \mathrm{a}$ \\
\hline
\end{tabular}

Different letters in each table row are significantly different at $P=0.05$

Leaf starch and sucrose metabolism progress was also affected by light environment (Fig. 2) [43]. The SS expression levels were significantly up-regulated under L and $\mathrm{L}+\mathrm{Fr}$ treatment (Table 1). However, an opposite trend was found in the gene expression pattern of Gmss1 under the L and L + Fr treatment (Fig. 6). Similarly, the sucrose level in low light condition decreased first due to decrease in the activities of sucrose synthesizing enzymes (i.e., SPS and SS-s) [44]. These results may be related to the different gene and protein expression levels for the same protein under different treatments.

\section{Conclusion}

These results suggested that low $\mathrm{R} / \mathrm{Fr}$ ratio (high enrichment of Fr light) in the same light intensity can increase the photosynthetic $\mathrm{CO}_{2}$ assimilation by improving the photosynthetic capacity.

\section{Methods}

\section{Plant materials and treatment design}

Nandou 12, which is a major soybean cultivar that is closely planted or intercropped with other crops in agriculture production in Southwestern China, was selected as the experimental material. Soybean seeds were provided by the Nanchong Institute of Agricultural Sciences, Sichuan Province, China. All soybean seeds were covered with wet filter paper for $24 \mathrm{~h}$ at $30^{\circ} \mathrm{C}$. After that, the germinated soybean seeds were grown in containers with a seedling spacing of $10 \mathrm{~cm}$. The size of each container was $15 \mathrm{~cm}$ in height, $40 \mathrm{~cm}$ in length, and $20 \mathrm{~cm}$ in width, and filled with humidified organic soil.

The experiment was divided into two parts. One part was used for morphology measurement. The containers including germinated seeds were directly placed under different light environment treatments, and each treatment included three containers.

The other part was used for physiological and proteomic analyses. The difference in soybean growth period under the various light environments was avoided by growing soybean under normal ambient condition, until the complete development of the first trifoliate leaf. Then, plants were subjected to four different light treatments just after the appearance of the second trifoliate. Furthermore, after 15 days of treatments, all samples were collected at $10 \mathrm{am}$ for the analysis of physiological parameters and differentially expressed proteins. Plants were grown in growth chamber with natural solar radiation, with the temperature maintained at $25{ }^{\circ} \mathrm{Cin}$ the day and $20^{\circ} \mathrm{C}$ during the night. Additionally, the humidity was maintained at $60 \%$, and plants were irrigated with nutrients solution ( $0.2 \%$ Hoagland's solution) after every couple of days [45].

The black nylon gauze and Far Red (Fr)-LED was used according to our previous knowledge [9], to control the PAR and Red-Far Red ration in soybean canopy. The intensity of $\mathrm{Fr}$ light in soybean canopy is $5.98 \pm$ $0.14 \mu \mathrm{mol} \cdot \mathrm{m}^{-2} \cdot \mathrm{s}^{-1}$ under dark condition. The PAR and spectral irradiance of soybean canopy were measured at noon on a sunny day, every measurement was replicated five times. The following four treatments were used (Table 2): normal light, normal light plus Fr light, low light, and low light plus far-red light. Every treatment was repeated three times in three different growth chambers. The PAR and spectral irradiance were measured using LI-190SA quantum sensors (LI-COR Inc., Lincoln, NE, USA) and a fiber-optic spectrometer (AvaSpec-2048; Avantes, Netherlands) placed at $10 \mathrm{~cm}$ above the soybean canopy, respectively $[7,9]$.

\section{Morphological characteristics}

The plant height from the soil surface to the growing point of soybean. The biomass and leaf area of five soybean seedlings were measured every 14 days after 14 days of sowing under four treatments. Leaves were scanned using a flatbed scanner (CanoScan LiDE 200, Canon Inc., Japan), and the leaf area $\left(\mathrm{cm}^{2}\right)$ was measured by Image J $1.45 \mathrm{~s}$. Biomass samples were over-dried at $105^{\circ} \mathrm{C}$ for $0.5 \mathrm{~h}$ to stop metabolic processes of tissues and then dried at $80^{\circ} \mathrm{C}$ for $72 \mathrm{~h}$ to a constant weight [9].

\section{Chloroplast ultrastructure}

As previously published by Yang et al. [11], the leaf segments $(2 \mathrm{~mm} \times 2 \mathrm{~mm})$ of second trifoliate were placed at $4{ }^{\circ} \mathrm{C}$ in $3 \%$ glutaraldehyde, and treated with $1 \%$ osmium tetroxide. Then, the fixed segments of soybean leaves were dehydrated and embedded in a graded acetone series and Epon812, respectively. The semithin sections were stained and cut with a diamond knife. Then, the samples were stained with acetate and lead citrate, and observed using a transmission electron microscope (TEM; HITACHI, H-600IV, Japan).

\section{Measurements of sucrose and starch}

Leaf samples were over- dried at $105^{\circ} \mathrm{C}$ for $0.5 \mathrm{~h}$ to stop metabolic processes of the tissues and then dried at 
$80^{\circ} \mathrm{C}$ for $24 \mathrm{~h}$ to a constant weight. According to the methods of Lee et al. (2020) with some changes [45], soluble sugars were extracted from $0.5 \mathrm{~g}$ dried samples by homogenization in $5 \mathrm{ml}$ of $80 \%(\mathrm{v} / \mathrm{v})$ ethanol. After heating the homogenate in a water bath, the insoluble fraction was removed by centrifugation at $3500 \mathrm{~g}$ for $10 \mathrm{~min}$. The precipitate was homogenized and centrifuged again. Supernatants were pooled and then diluted up to $25 \mathrm{ml}$ with $80 \%$ ethanol. The hydrolyzed samples were subjected to centrifugation, and only a small amount (100 $\mathrm{uL}$ ) of supernatant was collected and added with $100 \mathrm{uL}$ of $30 \%$ Potassium Hydroxide solution followed by boiling, about $10 \mathrm{~min}$. The solution was cooled down, and the anthrone agent was added. After heating the solution again at $40^{\circ}$ for $15 \mathrm{~min}$, it allowed to cool, and absorbance was checked at $620 \mathrm{~nm}$. The amount was calculated using the standard solutions of sucrose. The leftover material is centrifuged tube was utilized for starch extraction, by adding $2 \mathrm{~mL}$ of water. Then, the tubes were placed in boiling water bath for $15 \mathrm{~min}$. After cooling, 2 $\mathrm{ml}$ of $9.2 \mathrm{M}$ perchloric acid (PCA) was added. After stirring for $15 \mathrm{~min}$, the supernatants were collected after centrifuging the contents at $3500 \mathrm{~g}$ for $10 \mathrm{~min}$. The residues were re-extracted two times with $2 \mathrm{ml}$ of $4.6 \mathrm{M}$ PCA. After centrifugation, the supernatants were combined, volumes were made to $50 \mathrm{ml}$ with water. Starch was determined colorimetrically using the phenolsulphuric acid method, as described by [46].

\section{Photosynthesis, photosynthetic pigment concentration, and quantum yield of PS II}

As described by Yang et al. [2], the second trifoliolate leaf was selected to measure photosynthetic characteristics using a Li-6400 portable photosynthesis system (LICOR Inc., Lincoln, NE, USA), environment temperature $25^{\circ} \mathrm{C}$ and a $\mathrm{CO}_{2}$ concentration of $400 \mu \mathrm{mol} \mathrm{mol}^{-1}$ from 9:00 to 11:00. Eleven light intensity levels $(0,20,50,100$, 150, 200, 400, 600, 800, 1000, and $1200 \mu \mathrm{mol} \mathrm{m}^{-2} \mathrm{~s}^{-1}$ ) were imposed. On a light response curve, PPFD was located on the horizontal axis and $P_{n}$ was on the vertical axis $\left(P_{\mathrm{n}}\right.$-PPFD curve). The $P_{\max }$ and LSP were then estimated using the method proposed by Yang et al. [11]. Chlorophyll fluorescence parameters were obtained using a CI Imager chlorophyll fluorescence imaging system (Technologica Ltd., Colchester, UK). Before each measurement, we placed soybean leaves of each treatment under dark conditions for $10 \mathrm{~min}$. Then actinic illumination $\left(750 \mu \mathrm{mol} \mathrm{m}^{-2} \mathrm{~s}^{-1}\right)$ was switched on, and saturating pulses were applied at $20 \mathrm{~s}$ intervals for 15 $\mathrm{min}$. From each of these, the maximum fluorescence $\left(F^{\prime}\right.$ $\mathrm{m})$ and the steady-state fluorescence $\left(F_{\mathrm{s}}\right)$ were determined in the light condition. The quantum efficiency of the photosystem II was calculated according to the formula $\left(F_{\mathrm{m}}^{\prime}-F_{\mathrm{s}}\right) / F_{\mathrm{m}}^{\prime}[9]$.
After that, four-leaf disks of $15 \mathrm{~mm}$ diameter were obtained from the center of each leaf and then cut into pieces of $3 \mathrm{~mm}$. These leaf-disks were placed in $10 \mathrm{ml}$ of $80 \%$ acetone in the dark at $20^{\circ} \mathrm{C}$ for $24 \mathrm{~h}$. The chlorophyll contents were determined by following a previously published procedure [34]. Triplicates were prepared for each treatment.

\section{Protein extraction, digestion, and iTRAQ labeling}

After 2 weeks of treatment, the second leaf of soybean plants was ground using liquid nitrogen. Following the method of Yang et al. [11], the powder then shifted to a centrifuge tube. It fragmented using lysis buffer and 1\% protease suppressor cocktail under the cold condition with the help of a high-intensity ultrasonic processor (Scientz). The leftover was preceded by centrifugation. Proteins were sedimented under cold using 15\% TCA for $2 \mathrm{~h}$ at $-20^{\circ} \mathrm{C}$. Following centrifugation at $4{ }^{\circ} \mathrm{C}$, the afloat was disposed of, and the leftover sediment was rinsed three times using cold acetone. The protein concentration was then determined by dissolving the protein in the buffer. The reduction and alkylation of protein solution were done for $45 \mathrm{~min}$ using $20 \mathrm{mM}$ IAA at room temperature in the dark. $100 \mathrm{mM}$ TEAB was then used for the dilution of the protein sample. At last, for the digestion of protein, trypsin was added using the trypsinto-protein ratio. Approximately $100 \mu \mathrm{g}$ of protein was digested with trypsin in each sample for further experiments. For iTRAQ labeling, peptides were desalinized with the help of Strata X C18 SPE column (Phenomenex), vacuum-dried, replenished in 0.5 M TEAB, and then operated using 4-plex iTRAQ kit manual instructions.

\section{HPLC fractionation and LC-tandem mass spectrometry (MS/MS) analysis}

As previously reported [11], high $\mathrm{PH}$ reverse-phase HPLC divided the sample into fractions by using Agilent 300 Extend C18 column. Following the dehydration through vacuum centrifugation, the peptides were dissolved in $0.1 \%$ Formic Acid and loaded onto a reversephase analytical column (Acclaim PepMap RSLC, Thermo Scientific). EASY-nLC 1000 UPLC system was used to perform Gradient elution at a constant column flow rate of $350 \mathrm{nl} / \mathrm{min}$. The resulting peptides were then analyzed using an Orbitrap Fusion ${ }^{\mathrm{Tx}}$ Tribrid $^{\mathrm{Tw}}$ mass spectrometer (Thermo Fisher Scientific).

\section{Database search and analysis}

MaxQuant, with an integrated Andromeda search engine (v.1.5.2.8), was used to process the MS/MS data. iTRAQ 8-plex was used for the quantification, and the default values of all the other parameters in MaxQuant were selected, as reported by Yang et al. [11]. To identify the 
down-regulated or up-regulated protein expression, we used 0.77 - or 1.3 -fold cut-off with a $P<0.05$, respectively. GO annotation was used to annotate the proteins [23]. The differentially accumulated proteins were also assigned to the KEGG database [47, 48].

\section{qRT-PCR verification}

Proteomics reliability was confirmed by the help of qRTPCR assay. RNA isolation was done according to the protocol of Yuan et al. [49]. In our study, the $\beta$-tubulin gene was taken as a reference control. RT-PCR was done on a CFX96 system machine (Bio-Rad, USA). The primers used are listed in the Table S2.

\section{Statistical analysis}

Significance was calculated using one-way ANOVA by computer-based program SPSS (version 16.0). Data are given as mean \pm standard deviation from three replicates. Statistical significance was recognized at $P<0.05$.

\section{Supplementary information}

Supplementary information accompanies this paper at https://doi.org/10. 1186/s12870-020-02352-0.

Additional file 1: Figure S1. Light response curves of net photosynthetic rate (A), light saturation point (B), and quantum yield of PSII (C) of soybean leaves under different treatments. N, N + Fr, L + Fr, and $L$ denote normal light (normal PAR and normal R/Fr ratio), normal light plus far-red light (normal PAR and low R/Fr ratio), low light plus far-red light (low PAR and low R/Fr ratio), and low light (low PAR and normal R/ Fr ratio), respectively. $P_{\max }$ and LSP represent the maximum photosynthetic rate and the light saturation point. Data are expressed as the means \pm SD of triplicates. Means followed by different letters are significantly different at $P=0.05$

Additional file 2: Table S1. Differentially expressed statistics of unique proteins.

Additional file 3: Table S2. List of primers for characterizing Glycine max genes.

\section{Abbreviations}

Chl: Chlorophyll; GO: Gene Ontology; iTRAQ: Isobaric tags for relative and absolute quantification; KEEG: Kyoto Encyclopedia of Genes and Genomes; LSP: Light saturation point; $P_{\mathrm{n}}$ : Net photosynthesis rate; $P_{\max }$ : Maximum values of photosynthetic rate; qRT-PCR: Real-time quantitative polymerase chain reaction; $\mathrm{R} / \mathrm{Fr}$ : Red /Far-red ratio; PAR: Photosynthetically active radiation; POR: Protochlorophyllide reductase; PPFD: Photosynthetic photon flux density; PS I: Photosystem l; PS II: Photosystem II

\section{Acknowledgments}

We thank to Manager Yuanhong Deng of Jingjie PTM-Biolab (Hang Zhou 310018, China), Co., Ltd. for giving the suggestions on differentially expressed protein analysis.

\section{Authors' contributions}

$F Y, Q L$ and YC performed the experiment; LF, XWU and YF performed some experiments; FY, MAR, XW, TY, WL, JL, JB, KS and WY conceived the original research plans; $F Y$ and $W Y$ designed the experiments, analyzed the data, and wrote the article. All authors read and approved the final manuscript.

\section{Funding}

This work was supported by the National Nature Science Foundation (No. 31571615) and Program on Industrial Technology System of National Soybean (No. CARS-04-PS19). The funding bodies provided the financial support to this research, including experimental implementation, sampling and data analysis.

Availability of data and materials

The datasets used and analysed in this study are available from the corresponding author.

Ethics approval and consent to participate

Not applicable.

\section{Consent for publication}

Not applicable.

\section{Competing interests}

The authors declare that they have no competing interests.

\section{Author details}

${ }^{1}$ College of Agronomy, Sichuan Agricultural University, Huimin Road 211, Wenjiang District, Chengdu 611130, People's Republic of China. ${ }^{2}$ Sichuan Engineering Research Center for Crop Strip Intercropping System, Chengdu 611130, People's Republic of China. ${ }^{3}$ Key Laboratory of Crop Ecophysiology and Farming System in Southwest, Ministry of Agriculture, Chengdu 611130, People's Republic of China.

Received: 3 October 2019 Accepted: 23 March 2020

Published online: 08 April 2020

\section{References}

1. Yuan HY, Shyamali S, Albert V, Bett KE. Flowering and growth responses of cultivated lentil and wild lens germplasm toward the differences in red to far-red ratio and photosynthetically active radiation. Front Plant Sci. 2017;8: 386.

2. Yang F, Liao D, Wu X, Gao R, Fan Y, Raza MA, Wang X, Yong T, Liu W, Liu JJFCR: Effect of aboveground and belowground interactions on the intercrop yields in maize-soybean relay intercropping systems. 2017 203(Complete):16-23.

3. Feng Y, Wang X, Liao D, Lu F, Gao R, Liu W, Yong T, Wu X, Du J, Jiang LJAJ: Yield Response to Different Planting Geometries in Maize-Soybean Relay Strip Intercropping Systems 2015, 107(1):296.

4. Gelderen KV, Kang C, Paalman R, Keuskamp DH, Hayes S, Pierik RJPC: Far-red Light Detection in the Shoot Regulates Lateral Root Development through the HY5 Transcription Factor. 2018:tpc.00771.02017

5. Ballaré CL, Pierik RJPC, Environment: The shade avoidance syndrome: Multiple signals and ecological consequences 2017, 40.

6. Park Y, Runkle ESJE, Botany E: Far-red radiation promotes growth of seedlings by increasing leaf expansion and whole-plant net assimilation 2017, 136:41-49.

7. Feng Y, Shan H, Gao R, Liu W, Yong T, Wang X, Wu X, Yang WJFCR: Growth of soybean seedlings in relay strip intercropping systems in relation to light quantity and red:far-red ratio 2014, 155(155):245-253.

8. Ruberti I, Sessa G, Ciolfi A, Possenti M, Carabelli M, Morelli GJBA: Plant adaptation to dynamically changing environment: The shade avoidance response 2012, 30(5):1047-1058.

9. Yang F, Fan Y, Wu X, Cheng Y, Liu Q, Feng L, Chen J, Wang Z, Wang X, Yong TJFiPS: Auxin-to-Gibberellin Ratio as a Signal for Light Intensity and Quality in Regulating Soybean Growth and Matter Partitioning. 2018, 9:56-.

10. Li T, Liu LN, Jiang CD, Liu YJ, Shi LJJPPB: Effects of mutual shading on the regulation of photosynthesis in field-grown sorghum 2014, 137(8):31-38.

11. Feng $Y$, Feng L, Liu Q, Wu X, Fan Y, Raza MA, Cheng Y, Chen J, Wang X, Yong TJE et al: Effect of interactions between light intensity and red-to- farred ratio on the photosynthesis of soybean leaves under shade condition 2018, 150.

12. Park Y, Runkle ESJE, Botany E: Far-red radiation and photosynthetic photon flux density independently regulate seedling growth but interactively regulate flowering 2018, 155:206-216.

13. Demotes-Mainard S, Péron T, Corot A, Bertheloot J, Gourrierec JL, PelleschiTravier S, Crespel L, Morel P, Huché-Thélier L, Boumaza RJE et al: Plant responses to red and far-red lights, applications in horticulture 2015, 309.

14. Smith $H_{1}$. \%J Nature: Phytochromes and light signal perception by plants-an emerging synthesis. 2000, 407(6804):585-591. 
15. Wherley BG, Gardner DS, Metzger JDJCS: Tall Fescue Photomorphogenesis as Influenced by Changes in the Spectral Composition and Light Intensity 2005, 45(2):562-568.

16. Razzak MA, Ranade SS, Strand A, García-Gil MRJPC, Environment: Differential response of Scots pine seedlings to variable intensity and ratio of $R$ and FR light 2017, 40(8):1332.

17. Mccree KJJAM: The action spectrum, absorptance and quantum yield of photosynthesis in crop plants. 1971, 9(71):191-216.

18. Zhen S, lersel MWVJJoPP: Far-red light is needed for efficient photochemistry and photosynthesis. 2017, 209:115-122.

19. Duysens LNM, Amesz JJB-BeBA: Function and identification of two photochemical systems in photosynthesis. 1962, 64(2):243-260.

20. Wang L, Liang W, Xing J, Tan F, Chen Y, Huang L, Cheng C, Chen WJJoPR: Dynamics of Chloroplast Proteome in Salt-Stressed Mangrove Kandelia candel (L) Druce 2013, 12(11):5124-5136.

21. Deng X, Liu Y, Xu X, Liu D, Zhu G, Yan X, Wang Z, Yan YJFiPS: Comparative Proteome Analysis of Wheat Flag Leaves and Developing Grains Under Water Deficit 2018, 9

22. Zhang K, Liu H, Song J, Wu W, Li K, Zhang JJBPB: Physiological and comparative proteome analyses reveal low-phosphate tolerance and enhanced photosynthesis in a maize mutant owing to reinforced inorganic phosphate recycling 2016, 16(1):129.

23. Wang $\mathrm{L}$, $\mathrm{Cao} \mathrm{H}$, Chen $\mathrm{C}$, Yue $\mathrm{C}$, Hao X, Yang Y, Wang XJJoP: Complementary transcriptomic and proteomic analyses of a chlorophylldeficient tea plant cultivar reveal multiple metabolic pathway changes 2016, 130:160-169.

24. Yushan WU, Yang F, Gong W, Ahmed S, Fan Y, Xiaoling WU, Yong T, Liu W, Shu K, Liu JJJolA: Shade adaptive response and yield analysis of different soybean genotypes in relay intercropping systems 2017, 16(6):1331-1340.

25. Tacarindua CRP, Shiraiwa T, Homma K, Kumagai E, Sameshima RJFCR: The effects of increased temperature on crop growth and yield of soybean grown in a temperature gradient chamber 2013, 154:74-81.

26. Gong W, Jiang C, Wu Y, Chen H, Liu W, Yang WJP: Tolerance vs. avoidance: two strategies of soybean (Glycine max) seedlings in response to shade in intercropping. 2015, 53(2):259-268.

27. Gommers CMM, Visser EJW, Onge KR, St, Voesenek LACJ, Ronald PJTiPS: Shade tolerance: when growing tall is not an option 2013, 18(2):65-71.

28. Lewis CMJAJoB: The Dependence of the Quantum Yield of Chlorella Photosynthesis on Wave Lenghth of Light. 1943, 30(3):165-178.

29. Zhou H, Yu Z, Ye ZJSH: Key proteins associated to coloured compounds of peach peel using iTRAQ proteomic techniques during development and postharvest. 2018, 239:123-132.

30. Baginsky S, Gruissem WJJoEB: Chloroplast proteomics: potentials and challenges. 2004, 55(400):1213-1220.

31. Heyes DJ, Hunter CNJTiBS: Making light work of enzyme catalysis: protochlorophyllide oxidoreductase. 2005, 30(11):642-649.

32. Bennett J, Schwender JR, Shaw EK, Tempel N, Ledbetter MC, Williams RSJBeBA: failure of corn leaves to acclimate to low irradiance. Role of protochlorophyllide reductase in regulating levels of five chlorophyllbinding proteins 1987, 892(1):118-129.

33. Forreiter C, Van Cleve B, Schmidt A, Apel KJP: Evidence for a general lightdependent negative control of NADPH-protochlorophyllide oxidoreductase in angiosperms 1991, 183(1):126-132.

34. Sims DA, Gamon JAJRSoE: Relationships between leaf pigment content and spectral reflectance across a wide range of species, leaf structures and developmental stages. 2002, 81(2):337-354.

35. Chitnis VP, Ke A, Chitnis PRJPP: The PsaD Subunit of Photosystem I (Mutations in the Basic Domain Reduce the Level of PsaD in the Membranes). 1997, 115(4):1699-1705.

36. Nama S, Madireddi SK, Devadasu ER, Subramanyam RJJoP, B-biology P: High light induced changes in organization, protein profile and function of photosynthetic machinery in Chlamydomonas reinhardtii 2015, 152:367-376.

37. Srilatha N, Sai Kiran M, Elsin Raju D, Rajagopal SJJPPB: High light induced changes in organization, protein profile and function of photosynthetic machinery in Chlamydomonas reinhardtii. 2015, 152(Pt B):367-376.

38. Timperio AM, Gevi F, Ceci LR, Zolla LJPP, Biochemistry: Acclimation to intense light implies changes at the level of trimeric subunits involved in the structural organization of the main light-harvesting complex of photosystem II (LHCII) and their isoforms 2012, 50(1):8-14.

39. Ahmadova N, Mamedov FJPR: Formation of tyrosine radicals in photosystem II under far-red illumination. 2018, 136(1):93-106.
40. Ivanov AG, Sane PV, Simidjiev I, Park YI, Huner NPA, Öquist GJB-B: Restricted capacity for PSI-dependent cyclic electron flow in $\Delta$ petE mutant compromises the ability for acclimation to iron stress in Synechococcus sp. PCC 7942 cells is. 2012, 1817(8):1277-1284.

41. Okada KJB, Communications BR: PetH is rate-controlling in the interaction between $\mathrm{PetH}$, a component of the supramolecular complex with photosystem II, and PetF, a light-dependent electron transfer protein. 2009, 389(2):394-398.

42. Chuang-Dao J, Xin W, Hui-Yuan G, Lei S, Wah Soon CJPP: Systemic regulation of leaf anatomical structure, photosynthetic performance, and high-light tolerance in sorghum 2011, 155(3):1416-1424.

43. Gupta AK, Kaur NJJoB: Sugar signalling and gene expression in relation to carbohydrate metabolism under abiotic stresses in plants. 2005, 30(5):761-776.

44. Yang L, Chen J, Sun X, Li J, Chen N: Inhibition of sucrose and galactosylsucrose oligosaccharide metabolism in leaves and fruits of melon (Cucumis melo L.) under low light stress. Sci Hortic-Amsterdam. 2019;244:343-51.

45. Lee H, Lee BR, Islam MT, La VH, Park SH, Bae DW, Kim TH. Cultivar variation in hormone- and sugar-response reveals abscisic acid-responsive sucrose phloem loading at the early regenerative stage is a significant determinant of seed yield in Brassica napus. Environ Exp Bot. 2020;169:103917.

46. Dubois M, Gilles KA, Hamilton JK, Rebers PA, Smith FJAC: Colorimetric method for determination of sugars and related substances 1956, 28(3): 350-356.

47. Kanehisa M, Sato Y, Kawashima M, Furumichi M, Tanabe MJNAR: KEGG as a reference resource for gene and protein annotation 2016, 44(Database issue):D457-D462.

48. Yuan S, Zhang ZW, Zheng C, Zhao ZY, Wang Y, Feng LY, Niu GQ, Wang CQ, Wang $\mathrm{JH}$, Feng $\mathrm{H}$, et al. Arabidopsis cryptochrome 1 functions in nitrogen regulation of flowering. P Natl Acad Sci USA. 2016;113(27):7661-6.

49. Hoagland DR, Arnon DIJCaesc: The water-culture method for growing plants without soil. 1950, 347(5406):357-359.

\section{Publisher's Note}

Springer Nature remains neutral with regard to jurisdictional claims in published maps and institutional affiliations.

Ready to submit your research? Choose BMC and benefit from:

- fast, convenient online submission

- thorough peer review by experienced researchers in your field

- rapid publication on acceptance

- support for research data, including large and complex data types

- gold Open Access which fosters wider collaboration and increased citations

- maximum visibility for your research: over $100 \mathrm{M}$ website views per year

At $\mathrm{BMC}$, research is always in progress.

Learn more biomedcentral.com/submissions 